\title{
FOME COLETIVA NA VISÃO DE AMARTYA SEN COMO UM DOS FATORES IMPEDITIVOS DO DESENVOLVIMENTO HUMANO SUSTENTÁVEL
}

\section{COLLECTIVE HUNGER IN THE VISION OF AMARTYA SEN AS ONE OF THE IMPEDITIVE FACTORS OF SUSTAINABLE HUMAN DEVELOPMENT}

\author{
${ }^{1}$ Eduardo Torres Roberti \\ ${ }^{2}$ Raimundo Giovanni França Matos
}

\section{RESUMO}

O estudo tem por objeto a fome coletiva na visão de Amartya Sen como um dos fatores impeditivos do Desenvolvimento Humano Sustentável. Na visão do economista, a fome coletiva vai além da fome crônica, envolve um surto repentino de privação para uma parcela da população. Para eliminar a fome no mundo moderno, crucial enteder a causa das fomes coletivas de modo amplo, e não apenas em função de algum desequilíbrio mecânico entre alimentos e população. Ilustrando a privação de liberdade, traz-se o trabalho infantil como um dos fatores impeditivos do desenvolvimento humano sustentável.

Palavras-Chave: Fome Coletiva. Amartya Sen. Trabalho Infantil. Desenvolvimento Humano Sustentável. Fator impeditivo.

\begin{abstract}
The study aims at collective hunger in the vision of Amartya Sen as one of the impeding factors of Sustainable Human Development. In the economist's view, collective hunger goes beyond chronic hunger, involves a sudden outbreak of deprivation for a portion of the population. To eliminate hunger in the modern world, it is crucial to understand the cause of collective hunger in a broad way, and not just because of some mechanical imbalance between food and population. By illustrating the deprivation of liberty, child labor is included as one of the impediments to sustainable human development.
\end{abstract}

Keyword: Collective Hunger. Amartya Sen. Child Labor. Sustainable Human Development. Impedance factor.

\footnotetext{
${ }^{1}$ Mestrando em Direitos Humanos pela Universidade Tiradentes - Unit, Sergipe (Brasil). Professor da Universidade Tiradentes - Unit, Sergipe (Brasil). E-mail: eduardo@sradvs.com.br

${ }^{2}$ Doutorando em Direito pela Universidade Presbiteriana Mackenzie - Mackenzie, São Paulo (Brasil). Professor da Universidade Tiradentes - Unit, Sergipe (Brasil). E-mail: rg.adv@ hotmail.com
} 


\section{INTRODUÇÃO}

A questão central do presente estudo é a fome coletiva na visão de Amartya Sen como um dos fatores impeditivos do Desenvolvimento Humano Sustentável. Pautado pela ideia de que a fome coletiva, que diverge dos problemas de fome e pobreza endêmicas, envolve um surto repentino de grave privação para uma parcela considerável da população, onde é necessário, para a eliminação da fome no mundo moderno, entender a causação das fomes coletivas de um modo amplo, e não apenas em função de algum equilíbrio mecânico entre alimentos e população, pois uma pessoa pode ser forçada a passar fome mesmo havendo abundância de alimentos ao seu redor.(SEN, 2010, p. 210-211)

Para situar a análise do tema, o texto apresenta o Desenvolvimento Humano Sustentável que transcende do conceito de desenvolvimento econômico, estando intimamente ligado ao processo de capacitação das pessoas, correspondendo à melhoria qualitativa das condições de vida da população, sem deixar de mencionar que o desenvolvimento e o ambiente devem ser almejados de forma sustentável para que as pessoas possam viver de forma digna com melhoria de qualidade de vida.

Como forma ilustrativa, este estudo traz a perversidade do trabalho infantil como uma das mais violentas mazelas sociais contemporânea que impede profundamente que crianças, no período mais importante da evolução do homem - a sua infância, usufruam do desenvolvimento humano que lhes é peculiar.

Para ao final demonstrar que o trabaho infantil pode ser sim inserido no conceito de fome coletiva trazido pelo economista, sendo, portanto, um fator impeditivo de desenvolvimento humano sustentável.

\section{A FOME COLETIVA DE ACORDO COM AMARTYA SEN}

De acordo com o economista Amartya Sen (2010, p. 210) vivemos em um mundo assolado por fome e subnutrição disseminada e por repetidas fomes coletivas. E a falta de liberdade para remediar a fome pode levar ao fatalismo e à ausência de tentativas resolutas de sanar os sofrimentos que vemos.

Complementa o autor acima referendado que políticas e ações apropriadas podem realmente erradicar os terríveis problemas da fome no mundo moderno, tomando por base 
análises ecônimcas, políticas e sociais recentes, identificando, por sua vez medidas que podem levar à eliminação das fomes coletivas e uma redução radical da subnutrição crônica. (SEN, 2010, p. 210)

Esclare Sen (2010, p. 210) que as fomes coletivas e crises desse tipo tem de ser distinguidas dos problemas de forme e pobreza endêmicas que podem acarretar sofrimentos persistente, mas não incluem nenhuma nova exploração de privação extrema que subitamente acomete uma parcela da população.

Aponta Sen (2010, p. 211) que para eliminar a fome no mundo moderno, é de primordial importância entender a causação das fomes coletivas de um modo amplo, e não em função de algum equilíbrio mecânico entre alimentos e população.

Acrescentando o autor acima mencionado que o crucial ao analisar a fome é a liberdade substantiva do individuo e da família para estabelecer a propriedade de uma quantidade adequada de alimento, não relacionando a fome somente à produção de alimentos e expansão agrícola, mas também ao funcionamento de toda a economia e - até mesmo mais amplamente - com a acao das disposições politicas e sociais que podem influenciar, direta ou indiretamente, o potencial das pessoas para adquirir alimentos e obter saúde e nutrição. (SEN, 2010, p. 211)

Faz um alerta quando afirma a necessidade de concentração não na oferta de alimentos na economia, mas no intitulamento que cada pessoa desfruta, posto que as pessoas passam fome quando não conseguem estabelecer seu intitulamento sobre uma quantidade adequada de alimentos, trazendo 03 (três) aspectos que dedinem o intitulamento: na dotação - propriedade de recursos produtivos e riqueza que tem um preço no mercado (força do trabalho); na possibilidade de produção de seu uso - determinados pela tecnologia disponível e são influenciadas pelo conhecimento disponível e potencial das pessoas, e nas condições de troca de cada individuo - poder de vender e comprar. (SEN, 2010, p. 212-213)

Sen (2010, p. 222) traz à baila que a prevenção da fome coletiva depende muito das politicas de proteção aos intitulamentos.

A economia politica da prevenção da fome coletiva envolve instituições e organizações, mas depende, além disso, do exercício de poder e autoridade, depende, particularmente, do distanciamento entre governantes e governados, tendo esse distanciamento um papel crucial na ausência de prevenção contra uma fome coletiva. (SEN, 2010, p. 222) 
Veiga (2005) afima que o desenvolvimento requer que se removam as principais fontes de privação de liberdade, pobreza e tirania, carência de oportunidades econômicas e destituição social sistemática, negligência dos serviços públicos e intolerância ou interferência de Estados repressivos.

Sen (2010, p. 229) afirma que o senso de distanciamento entre o governante e o governado - entre nós e eles - é uma característica crucial das fomes coletivas.

Traz ainda o referido autor que é possível evitar as fomes coletivas recriando as rendas perdidas pelas vitimas potenciais, criando de forma temporária o empregado assalariado, dando-lhe poder para competir por alimentos no mercado, permitindo que as vitimas potenciais da fome coletiva sejam tratadas como agentes ativos, e não como recebedoras passivas de esmolas do governo. (SEN, 2010, p.232)

Sen (2010, p. 233) aborda ainda a democracia como forma de erradicar a fome, posto que é de conhecimento público e notório de que nunca houve uma fome coletiva em uma democracia multipartidária efetiva. Complementando ainda o mesmo autor que a democracia pode ser uma influência muito positiva na prevenção das fomes coletivas no mundo contemporâne. (SEN, 2010, p. 240)

Exemplifica o autor nos seguintes termos:

De fato, como já discutido, países democráticos a exemplo de Botsuana, India e Zimbábue têm tido êxito total na prevenção de fomes coleticas apesar de drásticos declínios na produção de alimentos e nos intitulamentos de grandes segmentos da população, ao passo que países não democráticos tem sofrido frequentes fomes coletivas apesar de situações muito mais favoráveis da oferta de alimentos. (SEN, 2010, p. 240)

No mesmo raciocício Piovesan (2015) afirma que não há direitos humanos sem democracia nem tampouco democracia sem direitos humanos. Vale dizer, o regime mais compatível com a proteção dos direitos humanos é o regime democrático.

Completa a autora acima que o direito ao desenvolvimento contempla 3(três) dimensões centrais: a primeira como sendo a justiça social, com base no artigo 28 da Declaração de Direitos Humanos, como um componente central à concepção do direito ao desenvolvimento. A realização do direito ao desenvolvimento, inspirado no valor da solidariedade, há de prover igual oportunidade a todos no acesso a recursos básicos, educação, saúde, alimentação, moradia, trabalho e distribuição de renda. 
A segunda dimensão a participação e accontabilitt, posto que além do componente de justiça social, o componente democrático é essencial ao direito ao desenvolvimento, sendo dever do Estado encorajar a participação popular em todas as esferas como um importante fator ao direito ao desenvolvimento e à plena realização dos direitos humanos.

E, por derradeira, programas e políticas nacionais e cooperação internacional, afirmando que o direito ao desenvolvimento compreende tanto uma dimensão nacional, como uma dimensão internacional, tomando por base a previsão da Declaração sobre o Desenvolvimento que os Estados devem adotar medidas - individuais e coletivamente - para criar um ambiente e permitir, nos planos internacional e nacional, a plena realização do direito ao desenvolvimento.

Portanto, o desafio do desenvolvimento inclui na eliminação da privação persistente e endêmica e a prevenção da distituição súbita e severa, e que a desigualdade tem um papel importante no desenvolvimento das fomes coletivas. (SEN, 2010, p. 243)

\section{O DESENVOLVIMENTO HUMANO SUSTENTÁVEL}

A Declaração sobre o Direito ao Desenvolvimento vem deixando um rastro de controvérsia desde que foi aprovada pelas Nações Unidas, em 1986.(NWAUCHE; NWOBIKE, 2005)

Bedin (2003) afirma que a Declaração Sobre o Direito ao Desenvolvimento adotada pela Resolução 41/128, é um documento bastante denso, mas relativamente enxuto em sua estrutura. Dentre outros aspectos, os parágrafos premabulares destacam os vínculos existentes entre a Declaração e os propósitos e princípios da Carta das Nações Unidas e entre a Declaração e vários outros instrumentos legais anteriores criados pela ONU.

Completa o mesmo autor, informando que além do exposto acima, os parágrafos preambulares explicita o que a Declaração entende por desenvolvimento e estabelece que paz e segurança internacionais são elementos essenciais à realização do direito ao desenvolvimento. (BEDIN, 2003)

Durante muito tempo, o pensamento dominante foi que desenvolvimento e crescimento econômico seriam a mesma coisa: bastava que uma comunidade produzisse riqueza, medida pelo Produto Interno Bruto (PIB), para ser considerada desenvolvida. (OLIVEIRA, 2006) 
Acreditava-se também que o crescimento econômico "transbordaria" dos ricos para os pobres e que, por isso, bastaria atrair e incentivar empresas - de preferência grandes - para desenvolver uma região. Os empregos seriam automaticamente criados, a arrecadação de imposto aumentaria, e todos ganhariam com isso, de acordo com a autora acima citada.

No mesmo sentido Veiga (2008, p.17) preleciona que a resposta mais frequente quando se indaga sobre crescimento é tratar o desenvolvimento como sinônimo de crescimento econômico.

Ocorre que esse tipo de constatação levou o Programa das Nações Unidas para o Desenvolvimento (PNUD) a propor um novo conceito: o do Desenvolvimento Humano Sustentável (DHS). Sem "reinventar a roda", resgatando ideias importantes para a humanidade, esse conceito diz que o ser humano é a razão de ser do desenvolvimento, e no ser humano devem estar centrados tanto o processo quanto os resultados inerentes ao desenvolvimento. (OLIVEIRA, 2006)

O desenvolvimento e o ambiente devem ser almejados de forma sustentável para que as pessoas possam viver de forma digna com melhoria da qualidade de vida, por meio do desenvolvimento econômico e da manutenção dos recursos ambientais. (FERNANDES, 2008)

Corroborando com esta nova proposta de conceito ao desenvolvimento, é mister entender que o desenvolvimento está intimamente ligado ao processo de capacitação das pessoas, compreendendo- se aí aspectos como a educação, o conhecimento, a justiça social, a participação pública, e o fortalecimento das instituições democráticas. (DELGADO, 2001, p.409).

Sen (2010, p. 16) afirma que o o desenvolvimento é compreendido como -um processo de expansão das liberdades reais que as pessoas desfrutam.

O direito ao desenvolvimento é um direito humano com fulcro no qual cada ser humano e os povos têm -o direito de participar, contribuir e gozar` desse processo de desenvolvimento. (SENGUPTA, 2002, p. 66).

A maior riqueza de um país, ou de qualquer território, é o povo que ali vive. E quanto maiores forem suas capacidades de escolher livremente, de liberar seu potencial, mais desenvolvido será um país, estado ou município. (OLIVEIRA, 2006)

A expansão da liberdade humana é tanto o principal fim como o principal meio do desenvolvimento, afimra Sen (2010, p. 76) 
E complementa o mesmo autor que o objetivo do desenvolvimento relaciona-se à avaliação das liberdades reais desfrutadas pelas pessoas. As capacidades individuais dependem crucialmente, entre outras coisas, de disposições econômicas, sociais e politicas. (SEN, 2010, p. 77)

O artigo $2^{\circ}$. da Declaração sobre o Direito ao Desenvolvimento de 1986, consagra que: "A pessoa humana é o sujeito central do desenvolvimento e deve ser ativa participante e beneficiária do direito ao desenvolvimento."

O desenvolvimento corresponde à melhoria qualitativa das condições de vida da população, pela transformação da economia, que passaria a corresponder a um modelo moderno, eficiente e inclusivo. (ANJOS FILHO, 2013)

Completa o referido autor que o processo de desenvolvimento altera não só estruturas econômicas e produtivas, mas também sociais, institucionais e políticas, significando aumento da produção acompanhado do incremento da renda e da capacidade econômica da população.

É possível haver desenvolvimento humano mesmo quando o crescimento econômico é baixo ou inexistente. Isso depende das prioridades estabelecidas para o gasto público e de quais políticas públicas são efetivamente implementadas. (OLIVEIRA, 2006)

O Desenvolvimento Humano Sustentável como novo paradigma, para o qual a vida humana tem importância pelo seu valor intrínseco e não porque as pessoas podem produzir bens materiais. (ANJOS FILHO, 2013)

O desenvolvimento compreende um processo econômico, social, cultural e político, -com o objetivo de assegurar a constante melhoria do bem-estar da população e dos indivíduos, com base em sua ativa, livre e significativa participação neste processo, orientado pela justa distribuição dos benefícios dele resultantes. (PIOVESAN, 2010, p. 102).

Dialogando nesse sentido Amartya Sen assim preleciona:

Os papéis instrumentais da liberdade incluem vários componentes distintos, porém inter-relacionados, como facilidades econômicas, liberdades politicas, oportunidades sociais, garantias de transparência e segurança protetora. Esses direitos, oportunidades e intitulamentos instrumentais possuem fortes encadeamentos entre si, que podem ser dar em diferentes direções. O processo de desenvolvimento é crucialmente influenciado por essas inter-relações. (SEN, 2010, p-77) 
Nesse mesmo sentido, o direito ao desenvolvimento invoca a noção de agente, no sentido de tomar para si a responsabilidade individual e coletiva pelos fatos que afetam o indivíduo. (SATIRO; MARQUES; OLIVEIRA, 2016)

Sendo, portanto, dever dos Estados encorajar a participação popular em todas as esferas como um importante fator ao direito ao desenvolvimento. (PIOVESAN, 2010, p. 103)

Sen (2010, p. 77) afirma que as pessoas têm de ser vistas como ativamente envolvidas - dada a oportunidade - na conformação de seu próprio destino, e não apenas como beneficiarias passivas dos frutos dos engenhosos programas de desenvolvimento.

Todas as vidas humanas têm a mesma importância, e nenhuma criança deveria ser condenada a uma vida curta ou miserável apenas porque nasceu em uma classe errada, em um país errado ou porque pertence ao sexo errado. (ANJOS FILHO, 2013)

Complementa ainda o mesmo autor que o objetivo do desenvolvimento, nesse contexto, é criar um meio ambiente no qual todas as pessoas possam expandir as capacidades potenciais que possuem desde o nascimento e as oportunidades possam também ser aumentadas para as presentes e futuras gerações.

Oliveira (2006) afirma que o conceito de Desenvolvimento Humano Sustentável foi especialmente concebido para superar a noção de que o desenvolvimento se limita ao crescimento econômico, a partir da idéia de que a utilidade da riqueza e da renda está nas liberdades que elas ajudam a obter.

Completa a mesma autora que o conceito de Desenvolvimento Humano Sustentável abrange meios e fins; justiça social e desenvolvimento econômico; bens materiais e o bemestar humano; investimento social e o empoderamento das pessoas; atendimento das necessidades básicas e estabelecimento de redes de segurança; sustentabilidade ambiental para as gerações atuais e futuras; e a garantia dos direitos humanos - civis, políticos, sociais, econômicos e ambientais.

\section{O TRABALHO INFANTIL E O DESENVOLVIMENTO HUMANO}

A atenção à criança e ao adolescente constitui o elemento central na formulação de qualquer plano de desenvolvimento social. Nesse contexto, o combate ao trabalho infantil se torna um dos principais desafios a serem superados. É auspicioso, portanto, que o assunto tenha se incorporado ao conjunto das grandes questões sociais da atualidade. (LEMBI, 2002, p. 145) 
O desenvolvimento humano é entendido como um processo de internalização de regras, de valores e de modos de pensar e de agir que ocorre nas interações sociais das quais o sujeito participa em seu dia-a-dia. (CAMPOS; FRANCISCHINI, 2003, p. 122)

E como premissa para o conceito trazido à baila, os mesmos autores indagam: como pensar esse processo em crianças e adolescentes que vivenciam, em seu contexto social, a realidade do trabalho precoce?

No plano internacional, a regulamentação do trabalho é atividade realizada pela Organização Internacional do Trabalho - OIT, através das Convenções e Recomendações por ela emanadas (SOUZA, 2006, p. 445).

Em artigo dedicado ao estudo da integração das normas emanadas pela OIT no Brasil, Mazzuoli conceitua "Convenção" da seguinte forma:

Tratados multilaterais abertos, de natureza normativa, elaborados sob os auspícios da Conferência Internacional do Trabalho, a fim de regulamentar o trabalho no âmbito internacional e também outras questões que lhe são conexas. (MAZZUOLI, 2013, p. 234)

Por sua vez, Mazzuoli (2013, p. 235) esclarece que as recomendações "não são tratados e visam tão somente sugerir ao legislador de cada um dos países vinculados à OIT mudanças no seu Direito Interno relativamente às questões que disciplina”.

Para que sejam as convenções internacionais incorporadas ao plano legislativo do Brasil, devem seguir o mesmo procedimento adotado com relação aos tratados. Isto é, para dar efeitos ao tratado internacional, este deve se submeter ao Congresso Nacional (art. 49, inciso I) para que posteriormente, se aprovado, ser ratificado pelo Presidente da República (MAZZUOLI, 2013, p. 238-242).

No Brasil, o tratamento dado pela Constituição da República Federativa de 1988 não se restringiu a enumerar direitos fundamentais a estas pessoas em desenvolvimento, mas também dedicou prioridade absoluta aos jovens. Nesse sentido, Rossato afirma que:

As crianças são titulares de direitos humanos, como quaisquer pessoas. Aliás, em razão de sua condição de pessoa em desenvolvimento, fazem jus a um tratamento diferenciado, sendo correto afirmar, então que são possuidoras de mais direitos que os próprios adultos. (ROSSATO, 2014, p. 49).

A abordagem protetiva dada pelo atual legislador constituinte pode ser verificada, de forma ampla, no artigo $6^{\circ}$, que abrigou o direito social da proteção à infância, assim como no 
artigo $7^{\circ}$, inciso XXXIII e artigo $227, \S 3^{\circ}$, incisos I e II, estes últimos relativos ao direito à profissionalização do menor.

Consoante o artigo $7^{\circ}$, inciso XXXIII, da CF/88, com a redação alterada pela Emenda Constitucional $n^{\circ} 20 / 1998$, proibiu-se o trabalho noturno, perigoso ou insalubre a menores de dezoito anos, e fixou em 16 anos a idade mínima para o ingresso no mercado de trabalho, salvo na condição de aprendiz, a partir dos 14 anos.

A citada proibição, nas palavras Ishida (2015, p. 175), tem como propósito o não comprometimento da formação educacional e familiar dos jovens, mormente considerando a adoção da doutrina da proteção integral pela Carta Política de 1988, em seu artigo 227, in verbis:

Art. 227. É dever da família, da sociedade e do Estado assegurar à criança, ao adolescente e ao jovem, com absoluta prioridade, o direito à vida, à saúde, à alimentação, à educação, ao lazer, à profissionalização, à cultura, à dignidade, ao respeito, à liberdade e à convivência familiar e comunitária, além de colocá-los a salvo de toda forma de negligência, discriminação, exploração, violência, crueldade e opressão.

Através deste dispositivo, observa-se que a Carta Magna conferiu direitos fundamentais às crianças e adolescentes, ao passo que instituiu atuação especial por parte da família, sociedade e do Estado. Assim, Rossato explica que:

[...] a família se responsabilize pela manutenção da integridade física e psíquica, a sociedade pelo desenvolvimento da convivência coletiva harmônica, e o Estado pelo incentivo à criação de políticas públicas (ROSSATO, 2014, p. 74).

Muito embora tenha o artigo 227 enumerado direitos fundamentais de aplicação imediata, o diploma legislativo de maior proteção infanto-juvenil, o ECA - Lei nº 8.069/1990, sistematizou a doutrina da proteção integral. regulamentando o metaprincípio da proteção integral logo em seu primeiro artigo: "Esta Lei dispõe sobre a proteção integral à criança e ao adolescente.”. Em seguida, conceitua criança como aquela pessoa entre 12 anos de idade incompletos, e adolescente aquela entre 12 e 18 anos de idade.

Todavia, nos artigos $3^{\circ}$ e 15 da Lei é que se verifica um grande avanço em relação às crianças e adolescentes, o reconhecimento destas como sujeitos de direitos:

Art. $3^{\circ}$ A criança e o adolescente gozam de todos os direitos fundamentais inerentes à pessoa humana, sem prejuízo da proteção integral de que trata esta Lei, assegurando-se-lhes, por lei ou por outros meios, todas as oportunidades e facilidades, a fim de lhes facultar o desenvolvimento físico, mental, moral, espiritual e social, em condições de liberdade e de dignidade. (...) 
Art. 15. A criança e o adolescente têm direito à liberdade, ao respeito e à dignidade como pessoas humanas em processo de desenvolvimento e como sujeitos de direitos civis, humanos e sociais garantidos na Constituição e nas leis.

Com efeito, o ECA, aliado à Constituição Federal, legitimou a condição peculiar dos jovens como cidadão em pleno desenvolvimento, conferindo-lhes, pois, o direito fundamental ao não trabalho.

Nessa linha de raciocínio, o ECA, de modo igual à Constituição, dispensou normas protetivas ao trabalho infantil, elencadas no Capítulo $\mathrm{V}$, Do direito à profissionalização e à proteção no trabalho, cujo título fora transcrito no art. 69 do diploma estatutário:

Art. 69. O adolescente tem direito à profissionalização e à proteção no trabalho, observados os seguintes aspectos, entre outros:

I - respeito à condição peculiar de pessoa em desenvolvimento;

II - capacitação profissional adequada ao mercado de trabalho.

Junta-se a essas legislações a Consolidação das Leis do Trabalho. A CLT possui capítulo próprio sobre o trabalho infanto-juvenil, vale dizer, o Capítulo IV, que dispõe sobre a Proteção do Trabalho do Menor, dos artigos 402 a 441.

O referido diploma, no mesmo sentido da Constituição Federal, reproduziu os mesmos critérios sobre o trabalho infantil, inclusive, ampliando-os. Isto é, a legislação obreira deu maior amplitude aos limites estabelecidos constitucionalmente em seu parágrafo único do artigo 403, o qual prevê: "O trabalho do menor não poderá ser realizado em locais prejudiciais à sua formação, ao seu desenvolvimento físico, psíquico, moral e social, e em locais que não permitam a frequência à escola.".

Tratou, também, de regular o contrato de aprendizagem, cuja modalidade contratual destina-se ao comprometimento pelo empregador de assegurar ao aprendiz maior de $14 \mathrm{e}$ menor de 24 anos, inscritos em programa de aprendizagem, formação técnico-profissional metódica, compatível com seu desenvolvimento físico, moral e psicológico, nos termos do artigo 428 da CLT:

Art. 428. Contrato de aprendizagem é o contrato de trabalho especial, ajustado por escrito e por prazo determinado, em que o empregador se compromete a assegurar ao maior de 14 (quatorze) e menor de 24 (vinte e quatro) anos inscrito em programa de aprendizagem formação técnicoprofissional metódica, compatível com o seu desenvolvimento físico, moral e psicológico, e o aprendiz, a executar com zelo e diligência as tarefas necessárias a essa formação. (Redação dada pela Lei $n^{\circ} 11.180$, de 2005). 
Contudo, em que pese reconheça-se a vontade do legislador do desenvolvimento educacional dos jovens, o trabalho infantil muita das vezes é informal, praticado às margens da legislação brasileira, em logradouros públicos, feiras livres, ambientes domésticos, o que dificulta ainda mais coibir a prática de exploração dos menores (BUENO, 2010).

Vale ressaltar que os atores sociais que deveriam cumprir suas funções atuam em sentido contrário ao que prevê a Constituição. Em verdade, as famílias incentivam o trabalho em idade precoce, na maioria dos casos, para complementar a renda familiar, em detrimento da educação das crianças e adolescentes (SOUZA, 2014).

Com isso, apesar de ser farta a quantidade de normas a respeito do trabalho infantil, há a falta de aplicabilidade dos direitos e garantias trazidos pelos diplomas abordados. (FERNANDES, 2007, p. 5511)

\section{CONSIDERAÇÕES FINAIS}

O presente estudo teve por objeto a fome coletiva na visão do economista Amartya Sen como uma das formas de impedimento do Desenvolvimento Humano Sustentável. De acordo com o referido autor a fome coletiva , como falta de liberdade do individuo, vai muito além da relação entre alimento e alimentado, ou seja, precisa ser distinguida dos problemas da fome e a pobreza endêmica, posto que, assolado por esta fome coletiva, o individuo é privado de obter o mínimo de condições favoráveis ao desenvolvimento.

Ainda, sobre a fome coletiva, o artigo aborda as formas de prevenção e/ou até mesmo as formas para erradicar a fome coletiva elencadas pelo Amartya Sem, trazendo como destaque o intitulamento que cada pessoa desfruta, posto que as pessoas passam fome quando não conseguem estabelecer o seu intitulamento; a economia política no envolvimento de instituições e organizações, dependendo do distanciamento dos governantes e governados; a criação das rendas perdidas pelas vitimas potenciais, permitindo que estas concorrarm no mercado, e, por fim, a democracia como fator determinante, enfatizando que o direito ao desenvolvimento possui 3 (três) dimensões centrais, dentre elas: a justiça social, a participação e accontabilitt e programas e políticas nacionais e cooperação internacional.

No tocante ao desenvolvimento, este trabalho aduz sobre o Desenvolvimento Humano Sustentável, partindo da premissa de que o DHS surgiu como oposição do desenvolvimento quanto crescimento econômico, tendo por sua vez um conceito amplo e intimamente ligado ao processo de capacitação das pessoas. 
O Programa das Nações Unidas para o Desenvolvimento (PNUD) propôs um novo conceito inserindo o ser humano como a razão de ser do desenvolvimento. Sendo o desenvolvimento compreendido como um processo de expansão das liberdades reais que as pessoas possam desfrutar.

A Declaração sobre o Direito ao Desenvolvimento de 1986 afirma que a pessoa humana deve ser ativa participante e beneficiária do direito ao desenvolvimento.

$\mathrm{O}$ desenvolvimento abordado corresponde à melhoria qualitativa das condições de vida da população, alterando além das estruturas econômicas e produtivas, as sociais, institucionais e políticas, sendo possível haver desenvolvimento mesmo quando o crescimento econômico é baixo ou inexistente.

E, por fim, para ilustrar a fome coletiva como fator impeditivo do Desenvolvimento Humano Sustentável, já que a fome coletiva é a privação da liberdade do indivíduo, este trabalho aborda acerca do trabalho infantil.

O trabalho infantil como sendo uma das mazelas sociais que merecem destaques, partindo da premissa de que a criança e o adolescente merecem atenção especial no plano de qualquer desenvolvimento social. Fazendo, em seu bojo, uma abordagem protetiva pelas Normas Internacionais, Carta Magna bem como legislações infraconstitucionais, como o ECA e a CLT.

\section{REFERENCIAS}

ANJOS FILHO, Robério Nunes dos. Direito ao desenvolvimento. São Paulo: Saraiva, 2013.

ASSEMBLEIA GERAL DAS NAÇÕES UNIDAS. Declaração sobre o direito ao desenvolvimento, 1986. Disponível em: http://direitoshumanos.gddc.pt/3_16/IIIPAG3_16_5.htm. Acesso em 14 jun. 2016.

BEDIN, Gilmar Antonio. Direitos Humanos e Desenvolvimento: algumas reflexões sobre a constituição do direito ao desenvolvimento. Desenvolvimento em Questão, v. 1, n. 1, p. 123-149, 2003. Disponível em https://revistas.unijui.edu.br/index.php/desenvolvimentoemquestao/article/view/70 Acesso em 16 de jun de 2016

BUENO, Tatiane Reyes. Erradicação do Trabalho Infantil... Uma utopia?. In: Âmbito Jurídico, Rio Grande, XIII, n. 81, out 2010. Disponível em:

http://www.ambitojuridico.com.br/site/index.php?n_link=revista_artigos_leitura\&artigo_id $=8501$. Acesso em 15 de jun 2016 . 
BRASIL. Constituição (1988). Constituição da República Federativa do Brasil: promulgado em 05 de outubro de 1988. Disponível em:

http://www.planalto.gov.br/ccivil_03/constituicao/constituicaocompilado.htm. Acesso em: 15 de jun. 2016

Decreto-lei $n^{\circ} .5 .452$, de $1^{\circ} .-5-1943$. Aprova a Consolidação das Leis do

Trabalho. Disponível em: http://www.planalto.gov.br/ccivil_03/decretolei/Del5452compilado.htm. Acesso em 14 de jun 2016.

Lei 8.069, de 13 de julho de 1990. Dispõe sobre o Estatuto da Criança e do

Adolescente, e dá outras providências. Disponível em:

http://www.planalto.gov.br/ccivil_03/LEIS/L8069.htm. Acesso em 13 de jun 2016.

CAMPOS, Herculano Ricardo; FRANCISCHINI, Rosângela. Trabalho infantil produtivo e desenvolvimento humano. Psicologia em Estudo, v. 8, n. 1, p. 119-129, 2003. Disponível em http://www.scielo.br/pdf/\%0D/pe/v8n1/v8n1a15.pdf Acesso em 12 de jun de 2016

DELGADO, Ana Paula Teixeira.O direito ao desenvolvimento na perspectiva da globalização: paradoxos e desafios. Rio de Janeiro: Renovar, 2001.

FERNANDES, Alana Gomes, WILLEMAM, Cyntia da Silva Almeida; POLICANI, Viviane Nogueira; RIBEIRO, Alessandra Florido da Silva. O estado, a família, a escola e a sociedade: os papéis sócio-institucionais na proteção da criança e do adolescente. In: XVI Congresso Nacional do Conpedi, Belo Horizonte, 2007, p. 5506 5526. Disponível em: http://www.publicadireito.com.br/conpedi/manaus/arquivos/anais/bh/alana_gomes_fernande s.pdf. Aceso em 15 de jun de 2016.

FERNANDES, Jeferson Nogueira. O direito fundamental ao desenvolvimento sustentável. Revista Direitos Fundamentais \& Democracia, v. 3, n. 3, 2008. Disponível em http://revistaeletronicardfd.unibrasil.com.br/index.php/rdfd/article/viewArticle/125 Acesso em 26 de jun de 2016

ISHIDA, Válter Kenji. Estatuto da criança e do adolescente: doutrina e jurisprudência. $16^{\mathrm{a}}$ ed. São Paulo: Editora Atlas, 2015.

LEMBI, Wilson Tarifa. Trabalho da criança e do adolescente: normas constitucionais e as regras da aprendizagem. Unimar, p. 145. Disponível em http://www.unimar.com.br/pos/rev_D/Direito_vol_02.pdf\#page=145. Acesso em: 15 de jun. 2016.

MAZZUOLI, Valerio de Oliveira. Integração das convenções e recomendações internacionais da OIT no Brasil e sua aplicação sob a perspectiva do princípio pro homine. Revista do Tribunal Superior do Trabalho, São Paulo, v. 79, n. 3, p. 233 254, jul./set. 2013. Disponível em:

http://aplicacao.tst.jus.br/dspace/bitstream/handle/1939/50181/013_mazzuoli.pdf?sequence $=1$. Acesso em 15 jun de 2016 . 
NWAUCHE, Eniynna S.; NWOBIKE, Justice C. Implementação do direito ao desenvolvimento. revista internacional de direitos humanos, p. 97, 2005. Disponível em http://www.dhnet.org.br/dados/revistas/sur/revista_sur_02.pdf\#page=97. Acesso em 16 de jun de 2016.

OLIVEIRA, Marielza. O desenvolvimento humano sustentável e os objetivos de desenvolvimento do milênio. RECIFE/PE. Desenvolvimento humano no Recife: Atlas Municipal. Seção Secretarias-Planejamento Participativo e Obras-Projetos e Ações. Disponível em: http://www. recife. pe. gov. br/pr/secplanejamento/pnud2006/doc/analiticos/desenvolvimentoh umano. pdf. Acesso em 14 de jun. 2016, v. 7, 2006.

PIOVEZAN, Flávia. Direito ao desenvolvimento: desafios contemporâneos. Revista da Faculdade de Direito de São Bernardo do Campo, v. 16, 2015. Disponível em http://www.ojs.fdsbc.servicos.ws/ojs/index.php/fdsbc/article/view/160 Acesso em 16 de jun de 2016.

PIOVESAN, Flávia. Direito ao desenvolvimento: desafios contemporâneos. In:

PIOVESAN, Flávia; SOARES, Inês Virgínia Prado (Coord.).Direito ao desenvolvimento.Belo Horizonte: Fórum, 2010.

ROSSATO, Luciano Alves; LÉPORE, Paulo Eduardo; CUNHA, Rogério Sanches. Estatuto da criança e do adolescente comentado artigo por artigo. $6^{\text {a }}$ Edição. Revista, ampliada e atualizada. São Paulo: Editora Revista dos Tribunais, 2014.

SÁTIRO, Guadalupe Souza; MARQUES, Verônica Teixeira; OLIVEIRA, Liziane Paixão Silva. O reconhecimento jurídico do direito ao desenvolvimento sob a perspectiva emancipatória dos direitos humanos/the juridical recognition of the right to development according to the emancipatory perspective of human rights (p. 2). Revista Jurídica Eletrônica da UFPI, v. 2, n. 02, 2016.Disponível em http://www.ojs.ufpi.br/index.php/raj/article/view/4669. Acesso em 13 de jun de 2016.

SEN, Amartya. Desenvolvimento como liberdade. Tradução Laura Teixeira Mota; revisão técnica Ricardo Doninelli Mendes. São Paulo: Companhia das Letras, 2010.

SENGUPTA, Arjun. O Direito ao desenvolvimento como um Direito Humano. Revista da Social Democracia Brasileira. No 68. Março de 2002.

SOUZA, José Alves. As consequências da exploração do trabalho infantil. In: Conteúdo Jurídico, Brasília-DF. Publicado em 16 maio de 2014. Disponível em: http://www.conteudojuridico.com.br/?artigos\&ver=2.48111\&seo=1. Acesso em: 15 de jun 2016.

SOUZA, Zoraide Amaral de. A organização internacional do trabalho: OIT. Revista da Faculdade de Direito de Campos, Campos dos Goytacazes, RJ, v. 7, n. 9, p.425 465, jul./dez. 2006. Disponível em: http://fdc.br/Arquivos/Mestrado/Revistas/Revista09/Artigos/Zoraide.pdf. Acesso em: 15 de jun de 2016. 
VEIGA, José Eli da. Desenvolvimento Sustentável: o desafio do século XXI. $3^{\text {a }}$ ed. Rio de Janeiro: Garamond, 2008. Disponível em https://books.google.com.br/books?hl=pt$\mathrm{BR} \& 1 \mathrm{r}=\& \mathrm{id}=\mathrm{hEj}$ cruYfChQC\&oi=fnd\&pg=PA15\&dq=Desenvolvimento+Sustent\%C3\%A1 vel\&ots=ua_Eeb37TV\&sig=lvWK4s0ux2eYiCxWqZzo43RSwaE\#v=onepage\&q=Desenvol vimento\%20Sustent\%C3\%A1vel\&f=false Acesso em 10 de jun de 2016

VEIGA, José Eli da. O prelúdio do desenvolvimento sustentável. 2005.Disponível em http://disciplinas.stoa.usp.br/pluginfile.php/253610/mod_resource/content $/ 1 /$ Texto $\% 2002 \%$ 20_\%20desenvolvimento_sustentavel.pdf Acesso em 10 de jun de 2016. 